\title{
Airedale Terrier
}

National Cancer Institute

\section{Source}

National Cancer Institute. Airedale Terrier. NCI Thesaurus. Code C53711.

The Airedale Terrier is a large terrier with a harsh wiry coat, long flat head, and a deep chest. The coat should be tan with black (or dark grizzle) markings. Height: 22-24 inches (56-61 cm.) Weight: 40-65 pounds (18-29 kg.) 